\title{
How can cultural sociology help us understand contemporary Chinese society?

\author{
Amy Tsang ${ }^{*}$ (D) and Michèle Lamont
}

\author{
* Correspondence: \\ amytsang@fas.harvard.edu \\ Department of Sociology, Harvard \\ University, 33 Kirkland Street, \\ Cambridge, MA 02138, USA
}

\begin{abstract}
In this editorial for the Thematic Series: Cultural Sociology and China, we discuss the global growth of cultural sociology as a sociological sub-discipline, its current state and future prospects in mainland China, and the aims of this special issue in promoting the subfield's further growth domestically in China.
\end{abstract}

Keywords: Cultural sociology, China, Sociology of knowledge

\section{Introduction: the global rise of cultural sociology}

For the last 40 years, American sociology has been transformed from the inside by the rapid growth of the study of culture, which includes (in short) both the study of meaning-making, identity, myths and narratives (cultural sociology) and the study of cultural institutions and cultural production, diffusion, and reception (the sociology of culture). We will refer to this field as "cultural sociology" for convenience.

From a relatively obscure, small, and marginal research area in the1970s and early 1980s, this field became central to American sociology a short decade later. Indeed, founded in 1988, the Culture Section of the American Sociological Association (ASA) rapidly grew to become one of the largest sections of the ASA by the mid-1990s, attracting more scholars than the Sex and Gender and Medical Sociology sections-the other two largest areas, with more than a thousand members each.

There are many other indicators of the intellectual vitality, centrality, and influence of cultural sociology besides section membership. Most significantly, all major sociology departments now have cultural sociologists on staff. By the mid-2000s, sociological theory was generally taught by cultural sociologists in top ten research departments (these departments train a significant portion of those who will teach sociology across the country). ${ }^{1}$ New specialized journals have emerged (e.g., American Journal of Cultural Sociology and Cultural Sociology) and older, more established journals, such as Poetics, have seen their impact factor increase significantly (reaching 1.649 in 2017, with a 5-year average of 2.280). The leading journal American Sociological Review is now co-edited by a cultural sociologist (Omar Lizardo) as are other high profile publications, such as Contemporary Sociology (Michael Sauder) and Sociological Forum (Karen Cerulo). Moreover, the "Princeton Series in Cultural Sociology" which Michèle Lamont has coedited at Princeton University Press for the last 20 years with three leaders of the field (Paul DiMaggio, Robert Wuthnow, and Viviana Zelizer)

(c) The Author(s). 2018 Open Access This article is distributed under the terms of the Creative Commons Attribution 4.0 International License (http://creativecommons.org/licenses/by/4.0/), which permits unrestricted use, distribution, and reproduction in any medium, provided you give appropriate credit to the original author(s) and the source, provide a link to the Creative Commons license, and indicate if changes were made. 
now includes a large number of prize-winning books that are widely regarded as representing the best of theoretically-informed systematic empirical research in contemporary American sociology. The popularity of cultural sociology has diffused beyond the USA, with stellar departments specializing in the field at leading institutions such as the London School of Economics, the University of Edinburgh, the University of Amsterdam, and the University of Toronto (among others).

The rapid development of cultural sociology is indicative not only of a growing interest in the systematic empirical study of cultural phenomena but also of the centrality of culture in the transformation of neighboring fields such as inequality, economic sociology, organizational sociology, the sociology of education, and sociological theory. For instance, culture concepts such as "frame," "narrative," "identity," "symbolic boundary," and "institutions" are increasingly central to the study of poverty and are transforming this area of research (Lamont et al. 2014, Small et al. 2010). Also, the scholarship of many of the leaders in these connate fields is now in dialog with cultural sociologynot only with the work of Pierre Bourdieu but also with that of many senior and mid-career scholars.

Among the defining characteristics of American cultural sociology is its methodological pluralism: sociologists working in the field tend to be multi-methods in orientation - that is, to mobilize equally qualitative and quantitative evidence. Indeed, network analysis is proving to be as central to the field as is observation, and both ethnography and interviews have been used in influential research (Lamont and Swidler 2014). Scholars engaged in the systematic analysis of cultural phenomena consider culture both as explanans or explanandum (cause and effect). Indeed, the field has operated as a big tent, leaving room for a variety of types of research. However, it has often been defined in contrast with cultural studies as it is practiced in humanities departments, because its goal is to identify regularities and to provide interpretation and explanation, as opposed to focusing more exclusively on close reading.

Given the effervescence and abundant scientific activity that has accompanied the growth of the field in the USA and Europe, it is surprising that cultural sociology has remained relatively underdeveloped in mainland China. ${ }^{2}$ While a number of overseas cultural sociologists have done research on cultural topics located in the Chinese context, ${ }^{3}$ the field itself remains rather underdeveloped within China. In contrast, this is not the case for the field of economic sociology, which is clearly recognized as a specialty, and which has benefited from the growing concern about phenomena such as consumption and market transition.

\section{The state of cultural sociology in China: slow but accelerating growth}

In preparing this introduction, we spoke with several Chinese scholars who have been pioneers in the field of cultural sociology, to gain a better understanding of the current situation. The consensus is that cultural sociology is generally viewed as a niche specialty that is poorly understood by the majority of Chinese sociologists. Most believe that the nascent state of the subdiscipline in the Chinese context is evidenced by the fact that the majority of Chinese sociology departments lack expertise in cultural sociological theory and few scholars self-identify as cultural sociologists (even fewer researchers would call themselves true experts in the field). However, interviewees know that a growing number of their colleague's research topics usually associated with 
cultural sociology in the West, from gender norms (Shen 2011; Choi and Peng 2016) to charitable giving practices (Zhou and Hu 2015), media discourses, and consumption to leisure and popular religion. However, lack of familiarity with the intellectual history and theoretical concepts that define the global subfield means that many of these colleagues do not self-identify as cultural sociologists nor engage with larger debates in the global sub-discipline. Still, awareness of cultural sociology spreading and our expert interviewees are optimistic concerning the potential for growth.

To explain the current state of cultural sociology in China, one must understand the recent history of sociology in China. According to an earlier pioneer of cultural sociology, Yi Zhou, a Professor of Sociology at Fudan University, timing explains the underdevelopment of the field and its relative isolation from global conversations: as cultural sociology was taking off in the West, Chinese sociology turned more quantitative (Chen 2017, 21) and became more focused on macro-sociological issues that were of direct relevance to the challenges that Chinese society faced in the 1980s and 1990s.

Again, interest in culture has by no means been completely foreign to the development of Chinese sociology. In the early days of the discipline's development in China between 1898 and 1949, many prominent scholars did attend to culture. For instance, Fei Xiaotong and Pan Guangdang's research on topics such as kinship and agrarian society paid attention to the cultural aspects of social life. However, all sociological research was put on hold between 1949 and the initiation of "Reform and Opening-up" in 1978. After that transition, Chinese sociology underwent a period of revival and reconstruction in the 1980s and 1990s. Grounded in empirical epistemology, the quantitative methodology was then able to gain traction, with a sustained focus on structural changes (Chen 2017, Zhou 2018). Again, these trends were shaped by the needs of domestic Chinese developments and by the priorities of the Chinese goverment.

Indeed, the discourses of modernization and "scientific" development became associated and pervasive in the early days of China's "Reform and Opening-up." While state-led efforts to reconstruct and professionalize the social sciences often held up the natural science as models (Chen 2017), these foci encouraged the development of quantitative methods and technical skill. Heavy state investment into large-scale survey data-collection also promoted the status of quantitative research over qualitative analysis (Chen 2017, 29). At the same time, the dramatic nature of market reforms initiated in 1979 captured domestic attention. This helped focus the attention of sociologists on the social structural effects of marketization and other macro-structural topics of research. Sociological research on stratification, economic transformation, and political reform thrived in this environment. Cultural sociology did not.

However, cultural sociology has found a more favorable environment in recent years. Indeed, Chinese sociological research gradually became decidedly more methodologically and substantively pluralistic. Qualitative research is now more widely practiced and growing attention is given to a wider range of social issues, such as gender, family, identity, and consumption. According to Zhou (2018), two major trends have promoted these changes. First, China has matured developmentally. As the initial stages of economic reforms have passed, interest in their micro-level and cultural impacts has developed. Studying culture is now seen to align with current national priorities of promoting Chinese cultural development, including leisure, tourism, quality of life and subjective well-being. 
A second force enabling change has been the increasing global embeddedness of Chinese sociology. Growing numbers of Chinese scholars travel abroad as graduate students and visiting scholars, and the community of diasporic Chinese scholars abroad is increasingly connected internally and externally. Both movements facilitate the circulation of information and a greater intellectual cross-pollination across national intellectual fields. At the same time, foreign sociologists are visiting China in growing numbers and many are developing collaborative relationships with Chinese institutions, as this current special guest-edited issue of The Journal of Chinese Sociology demonstrates. In particular, the Chinese Sociological Association has been eager to engage with other national associations, such as the European Sociological Association and the American Sociological Association, and has facilitated conversation and exchanges in the context of its national congresses. These developments have promoted an openness to diverse sociological ideas and a greater awareness of international trends in the discipline.

Our interviewees mentioned several indicators that suggest the growing penetration of cultural sociology in China. First, the number of culture-related Chinese publications has grown, as has the number of China-based scholars doing culture-related research. There are also signs that the subfield is becoming increasingly methodological pluralist, as both quantitative and qualitative research are now being conducted. While the growth of cultural sociology in China had been driven by the efforts of a few individual scholars with little institutional backing, in recent years, Chinese cultural sociology has become more organized. It is proving to be better at mobilizing institutional resources and of gaining recognition.

For instance, the Culture Section of the Chinese Sociological Association has grown to around 40 members, and more sociology departments are hiring cultural sociologists. Resources are now available to fund specialized guest lecturers and research centers such as the Yale-Fudan Center for Research in Cultural Sociology (a partnership between Yale University and Fudan University initiated in 2017). The Institute of Sociology at the Chinese Academy of Social Sciences is consecrating a special issue to cultural sociology and is also recognized by a prominent and highly influential academic organization. Our interviewees believe that better domestic graduate training in qualitative and interpretive methods will be needed to sustain the growth of the field. They are confident that cultural sociology has much to offer Chinese sociology as a whole and, conversely, that research on China can enrich cultural sociological theory as well.

\section{This special thematic series}

Our objectives in organizing this special themed journal issue are threefold. First, we aim to update knowledge in China about China-focused research influenced by American and European cultural sociology. Second, we wish to boost the visibility and growth of cultural sociology as a subdiscipline in China. Third, we wish to foster two-way dialog between global cultural sociology and Chinese sociology. Towards this end, the five papers in this special issue reflect a number of key developments in the field in the USA and Europe. At the same time, they also illustrate how cultural sociological theory and scholarship on contemporary China may mutually enrich one another.

A common misconception is that "cultural sociology" is limited to the study of cultural objects and industries themselves; in reality, as mentioned above, it attends to meaning-making and to the cultural dimensions of all domains of social life. 
Accordingly, articles in this issue demonstrate the full breadth of the field and that cultural meanings and processes are important dimensions of countless other aspects of social life (Alexander 2003). For instance, Wanning Sun's paper shows the importance of cultural practices of consumption, in this case of bridal photos and engagement rings, in the construction of class boundaries in a changing China. While not a cultural sociologist, Sun speaks to important topics in the field. In their paper on breastfeeding among urban Shanghainese women, sociologists Hanser and $\mathrm{Li}$ attend to cultural meanings of what Blair-Loy (2005) calls norms of "intensive motherhood" and adds an important dimension to the sociology of parenting and gender in China. Otis and Wu's ethnographic work enriches the study of organizational inequality by examining how collective, stratified "rural" and "urban" identities gain salience in a Chinese retail store. And through a survey of netizens engaging in online humor, Yates and Hasmath enrich our understanding of the formation of networks and the role of the internet in contemporary Chinese society.

Our authors build upon and extend well-known theoretical ideas from influential previous research in cultural sociology. For instance, Hanser and Li extend Ann Swidler's well-known metaphor of culture as a "toolkit," to shed light onto how it plays out in a gendered, "unsettled" social context (Swidler 1986). Sun's article invokes earlier work at the intersection of cultural and economic sociology to discuss ritual consumption (Zelizer 2010). Otis and Wu attend to "boundary work" (Lamont and Molnár 2002) and collective identities while introducing the new concept of "service capital" and referencing work on how cultural processes contribute to social stratification (Small et al. 2010). For their part, Yates and Hasmath challenge existing assumptions about the social functions of subversive humor, connecting it to research on social networks in society. These contributions demonstrate not only the relevance of common cultural sociological concepts for the analysis of Chinese contexts but also the ways in which honing in on the distinctive features of Chinese cases can enrich sociological knowledge on under-researched dimensions of well-known theoretical ideas.

This is particularly the case for Xiaoying Qi's paper: she argues that the study of cases from Chinese and other non-Western cultures can challenge existing assumptions and conventions in the application of existing sociological theories. She illustrates this point by showing how the variety of Chinese conceptions of "face" allow us to capture a more nuanced view of its collective and relational dimensions, extending beyond the individual dimensions theorized by the prominent theorists like Erving Goffman. The interplay of the various Chinese terms, lian and mianzi (two different words that mean "face"), offer sociologists a more sophisticated way to capture the relationship between individual agency and group affiliation. Thus, she offers a powerful example of how China-based empirical work makes contribution to general sociological theorizing.

It should also be noted that several of the papers (e.g., those by Qi, Hanser and Li, Sun, and Otis and $\mathrm{Wu}$ ) draw on in-depth interviews and ethnographic evidence to develop rich interpretation of the cases at hand. Yet, cultural sociology is also growing with the spread of quantitative and computational methods to analyze cultural phenomena and cultural meaning structures (Mohr 1998; Bail 2014). Thus, the field is well-positioned to remain not only relevant but essential in the age of big data age; it offers unique theoretical frameworks and conceptual tools to help us make sense of the massive volumes of data being produced in the internet age. Yates and Hasmath's 
analysis of the engagement of Chinese netizens with internet humor through the lens of network society is exemplary of the benefits of methodological pluralism for the field's growth. This expansion can go hand-in-hand with the simultaneous growth of other research areas.

\section{Conclusions}

Unfortunately, by necessity, this special issue does not reflect the full breath of important research being conducted in cultural sociology. Most importantly, we have chosen to showcase recent, cutting-edge work by scholars who study Chinese society but from outside mainland China. ${ }^{4}$ As Western-based scholars, we have chosen to more deeply delve into one part of the global conversation we seek to promote between global cultural sociologists and domestic Chinese scholars: overseas-based scholars talking to and about China for a global audience. We have done this with the knowledge that other facets of the conversation have and will be carried out in other forums. To take only one important example, the recently-published inaugural issue of Fudan University's Chinese language 社会学刊 (Journal of Sociological Studies) has been centered around cultural sociology, featuring a number of papers authored by Chinese scholars intended for a Chinese-speaking audience. The future should give rise to more publications, conferences, courses, and joint projects in which Chinese and overseas cultural sociologists converse with one another more directly.

Another area not covered in our special issue suggests directions for future research. All of the papers featured in our special issue focus solely upon China. And overall, few cultural sociological works we are familiar with situate Chinese cases within a comparative study or within a transnational theoretical framework (see Hoang (2015) for an example pertaining to Vietnam). It is our hope that cultural sociological work on China will mature by moving beyond the currently-dominant area-studies paradigm, one in which the Chinese case is frequently regarded as an extreme or an anomaly for the purposes of theory building. More research that situates Chinese phenomena within comparative and transnational frameworks will serve to normalize rather than exoticize Chinese social phenomena. It may take time for the subfield of cultural sociology to mature in China so as to enable more dialog with sociology as practiced elsewhere. But we hope that this special issue, along with other similar initiatives, will facilitate future exchanges and deeper engagement.

\section{Endnotes}

${ }^{1}$ As argued in Lamont (2004).

${ }^{2}$ Because the focus of this issue is mainland China, when not specified, "China" refers to mainland China and "Chinese sociology" refers to the sociological discipline within the mainland.

${ }^{3}$ For instance, the prize-winning book by Lei (2017).

${ }^{4}$ In focusing on newer research conducted by younger scholars, we have forgone, by necessity, the opportunity to feature culture-related work by a number of pioneering China-focused sociologists in the West that has inspired work by subsequent generations of scholars, including Deborah Davis' research on consumption and marriage, Richard Madsen's work on morality and religion, and Martin Whyte's 
research on familial life and subjective views on inequality (Davis 2000; Davis and Friedman 2014; Madsen 1984, 1998; Whyte 1997, 2010).

\section{Abbreviation}

ASA: American Sociological Association

\section{Acknowledgements}

We thank Professor Yi Zhou of Fudan University for her comments.

\section{Availability of data and materials}

Not applicable.

\section{Authors' contributions}

Author one played a primary role in researching and drafting pages 5-14 of the article. Author two outlined the article's structure, drafted pages 1-4, and edited the article for clarity. Both authors read and approved the final manuscript.

\section{Authors' information}

Michèle Lamont is a Professor of Sociology and of African and African-American Studies, the Robert I. Goldman Professor of European Studies, and the Director of the Weatherhead Center for International Affairs at Harvard University. She served as the 108th President of the American Sociological Association in 2016-2017, and she chaired the Council for European Studies from 2006 to 2009. She is also the recipient of the 2017 Erasmus prize for her contributions to the social sciences in Europe and the rest of the world. A cultural and comparative sociologist, Lamont has written on a range of topics including culture and inequality, racism and stigma, academia and knowledge, social change and successful societies, and qualitative methods.

Amy Tsang is a Doctoral Candidate in Sociology at Harvard University. Long interested in cultural sociology and contemporary China, her research interests lie at the intersection of culture, stratification, migration, and urban development. Her research has been supported by the National Science Foundation, The Chiang Ching-kuo Foundation for International Scholarly Exchange, and the China Scholarship Council of the Ministry of Education of the People's Republic of China.

\section{Competing interests}

The authors declare that they have no competing interests.

\section{Publisher's Note}

Springer Nature remains neutral with regard to jurisdictional claims in published maps and institutional affiliations.

Received: 12 September 2018 Accepted: 28 September 2018

Published online: 25 October 2018

\section{References}

Alexander, Jeffrey C. 2003. The meanings of social life: A cultural sociology. New York: Oxford University Press.

Bail, Christopher A. 2014. The cultural environment: Measuring culture with big data. Theory and Society 43 (3-4): 465-482. Blair-Loy, Mary. 2005. Competing devotion. career and family among women executives. Cambridge, MA: Harvard University Press.

Chen, Hon Fai. 2017. Chinese sociology: State-building and the institutionalization of globally circulated knowledge. 1st ed. 2018 edition. London, United Kingdom: Palgrave Macmillan.

Choi, Susanne, and Winni Peng. 2016. Masculine compromise. Migration, family and gender in China. Berkeley, CA: University of California Press.

Davis, Deborah S. 2000. The consumer revolution in urban China. Berkeley, CA: University of California Press.

Davis, Deborah S., and Sara L. Friedman. 2014. Wives, husbands, and lovers: Marriage and sexuality in Hong Kong, Taiwan, and urban China. Stanford, CA: Stanford University Press.

Hoang, Kimberly. 2015. Dealing in desire : Asian ascendancy, Western decline, and the hidden currencies of global sex work. Oakland, California: University of California Press.

Lamont, Michèle. 2004. The Theory Section and Theory Satellites. Perspectives. Newsletter of the ASA Theory Section 27(1):1-7.

Lamont, Michèle, Stefan Beljean, and Matthew Clair. 2014. What is missing? Cultural processes and causal pathways to inequality. Socio-Economic Review 12 (3): 573-608.

Lamont, Michèle, and Virág Molnár. 2002. The study of boundaries in the social sciences. Annual Review of Sociology 28 (1): 167-195.

Lamont, Michèle, and Ann Swidler. 2014. Methodological pluralism and the possibilities and limits of interviewing. Qualitative Sociology 37 (2): 153-171.

Lei, Ya-Wen. 2017. The contentious public sphere. In Law, media and authoritarian rule in China. Princeton, NJ: Princeton University Press.

Madsen, Richard. 1984. Morality and power in a Chinese village. Berkeley, CA: University of California Press.

Madsen, Richard. 1998. China's Catholics: Tragedy and Hope in an emerging civil society. Berkeley, CA: University of California Press, Mohr, John. 1998. Measuring meaning structures. Annual Review of Sociology 24(1):345-370.

Shen, Yifei. 2011. China in the 'post-patriarchal era'. Chinese Sociology and Anthropology 43 (4): 5-23.

Small, Mario L., David J. Harding, and Michèle Lamont. 2010. Introduction: reconsidering culture and poverty. The Annals of the American Academy of Political and Social Science 629: 6-27.

Swidler, Ann. 1986. Culture in action: symbols and strategies. American Sociological Review 51: 273-286.

Whyte, Martin King. 1997. The fate of filial obligations in urban China. The China Journal 38:1-3. 
Whyte, Martin King. 2010. Myth of the social volcano: Perceptions of inequality and distributive injustice in contemporary China. Stanford University Press.

Zelizer, Viviana A. 2010. Economic lives: How culture shapes the economy. Princeton, N.J.: Princeton University Press.

Zhou, Yi. 2018. "Daolun: Wenhua shehuixue de ersanshi." ("Introduction: A few thoughts on cultural sociology"). Shehuixuekan (Journal of Sociological Studies) 1:1-14. (in Chinese).

Zhou, Yi, and Anning Hu. 2015. Capital with beliefs-A study of charitable donations of private business owners in Wenzhou, China. The Journal of Chinese Sociology 2: 8.

Submit your manuscript to a SpringerOpen ${ }^{\odot}$ journal and benefit from:

- Convenient online submission

- Rigorous peer review

- Open access: articles freely available online

- High visibility within the field

- Retaining the copyright to your article

Submit your next manuscript at $\boldsymbol{\nabla}$ springeropen.com 